\title{
Argumentação e sociocognição nos discursos da Comunidade de Países de Língua Portuguesa
}

\section{Renata Palumbo}

Doutora pelo Programa de Pós-Graduação em Filologia e Língua Portuguesa da Universidade de São Paulo (USP), Brasil. Docente do Centro Universitário Carlos Drummond de Andrade. prof.renata.palumbo@gmail.com

Resumo: Examinamos as ocorrências de formulações linguísticas relacionadas ao objeto de discurso Língua Portuguesa com vista à participação da metáfora da personificação e do esquema LIGAÇÃO na argumentação política dos discursos oficiais dos paísesmembros da Comunidade de Países de Língua Portuguesa (CPLP). Estabelecemos interface entre os estudos acerca da sociocognição e da metáfora conceptual (LAKOFF e JOHNSON, 1980, CHILTON e LAKOFF, 2005, LAKOFF, 2009, CHARTERIS-BLACK, 2011, 2014, TURNER, 2014, VAN DIJK, 2016) e os preceitos da Nova Retórica (PERELMAN e OLBRECHTS-TYTECA, 2002 [1958]). Os resultados apontam para a construção da Língua Portuguesa como objeto de acordo e de poder nos discursos da CPLP.

Palavras-chave: Argumentação. Metáfora Conceptual. Discurso Político. Comunidade dos Países de Língua Portuguesa.

Abstract: We examine the occurrences of linguistic formulations related to the object of discourse Portuguese language aiming at understanding how the personification metaphor and the LINK schema operate in the political argumentation produced in the official discourses of the members of the Community of Portuguese-speaking Countries (CPLP).We have established an interface between the studies about sociocognition and conceptual metaphor (LAKOFF and JOHNSON, 1980, CHILTON and LAKOFF, 2005, LAKOFF, 2009, CHARTERIS-BLACK, 2011, 2014, TURNER, 2014, VAN DIJK, 2016) and the precepts of New Rhetoric (PERELMAN AND OLBRECHTS-TYTECA, 2002 [1958]). The results point to the construction of the Portuguese Language as an object of agreement and power in the speeches of the Community of Portuguese-speaking Countries.

Keywords: Argumentation. Conceptual Metaphor. Political Discourse. Community of Portuguese-speaking Countries. 
Introdução

A construção da Língua Portuguesa via discursos proferidos por chefes de Estado ou de Governo em encontros da Comunidade de Países de Língua Portuguesa (CPLP) faz parte de uma disputa por uma ocupação de destaque no cenário internacional, tendo em vista que quanto mais o Português é reconhecido como forte, tanto mais o Estado no qual a língua é oficial se fortalece; e vice-versa. Como parte do quadro de referências dos discursos políticos da CPLP, a Língua Portuguesa vem sendo utilizada como objeto de acordo na negociação de parcerias e de ações estratégicas entre os paísesmembros, tornando-se suscetível a construções de sentido de caráter argumentativo.

Tendo em vista que essas práticas discursivas estão inseridas em cenários de embate de forças e de busca constante por legitimação diante de auditórios complexos e diversificados, pressupomos que as seleções lexicais que se voltam para a Língua Portuguesa no interior de processos de referenciação agem, argumentativamente, de um modo peculiar à política global, uma vez que a construção de objetos de discursos, nesses encontros, deve atender às especificidades do conjunto de pessoas a quem os discursos são dirigidos no que diz respeito à cultura, à história e à distância geográfica.

É a partir desses pressupostos que nossa pesquisa tem como objetivo examinar como metáforas e esquemas participam da construção do objeto de discurso Língua Portuguesa nos discursos oficiais da CPLP e como atuam na argumentação dessas práticas discursivas. Buscamos uma discussão teórica por meio da qual pudéssemos situar o lócus da metáfora e dos esquemas em uma dimensão sociocognitiva e argumentativa. Desse modo, estabelecemos um diálogo entre os estudos acerca da sociocognição e da metáfora conceptual (LAKOFF e JOHNSON, 1980. CHILTON e LAKOFF, 2005, LAKOFF, 2009, CHARTERIS-BLACK, 2011, 2014, TURNER, 2014, VAN DIJK, 2016) e as pesquisas sobre argumentação (PERELMAN e OLBRECHTS-TYTECA, 2002 [1958]).

Em relação ao corpus desta pesquisa, investigamos documentos oficiais e discursos escritos que tiveram como tópico a Língua Portuguesa e que foram pronunciados em reuniões políticas internacionais com a presença de um ou mais países da CPLP, dentre os quais selecionamos dez para análise. A coleta deu-se nos acervos constantes do sítio do Itamaraty, da CPLP e dos 


\section{$\mathrm{EI} \square \mathrm{dA}$}

oficiais dos outros Estados-membros. Para este trabalho, examinamos os discursos escritos de José Sarney (2006), de José Luís Guterres (2011), de Dilma Rousseff (2012), de Taur Matan Ruak (2015).

A partir de um tratamento metodológico qualitativo dos dados, procedemos aos seguintes passos de investigação: a) localização de ocorrências de formulações linguísticas e metafóricas, relacionadas ao objeto de discurso Língua Portuguesa; b) análise do caráter argumentativo dessas ocorrências com a atenção voltada para a argumentação política internacional.

Dividimos este trabalho em três partes: primeiramente, discutimos algumas relações possíveis entre os estudos da argumentação e os da cognição pessoal, social e corporificada com vista à prática discursiva da política internacional; posteriormente, analisamos alguns discursos pronunciados por chefes de Estado em reuniões da CPLP, atentando-nos, respectivamente, à metáfora de personificação e ao esquema LIGAÇÃO, em razão de se apresentarem como procedimentos recorrentes nos discursos sob análise.

\section{Argumentação da política global e sociocognição: possíveis interfaces}

O discurso pode ser considerado uma ação por meio da qual o poder se constitui, haja vista sua força de atrair ou de separar pessoas de determinados grupos via um processo de organização e de categorização do mundo, que direciona, também, a moralidade e a memória da sociedade. A esse respeito, Lakoff (2009, p.231) afirma que:

A linguagem tem força moral; pode trazer o melhor das pessoas e o pior. Memórias nunca são apenas "armazenadas"; elas são sempre criadas novamente. A linguagem não apenas evoca memórias; pode mudá-las e moldálas e, assim, mudar a história - a história do passado. ${ }^{1}$

O estudioso segue afirmando que a linguagem corresponde a uma fonte de poder político em ocasiões em que seu uso leva à moldagem do pensamento - efeito extremamente central para a argumentação. $\mathrm{O}$ autor diz que essa prática linguageira de caráter persuasivo acontece, com frequência,

\footnotetext{
${ }^{1}$ No original: Language has moral force; it can bring out the best in people and the worst. Memories are never just "stored"; they are always created anew. Language does not just evoke memories; it can change them and shape them, and thereby change history - the story of the past.
} 
por meio da seleção de metáforas conceptuais e protótipos ${ }^{2}$, ativação de frames $^{3}$, apresentações de narrativas, construção de imagens mentais e suscitação de emoções.

A repetição desses procedimentos pode levar pessoas a ativarem, recorrentemente, determinados quadros mentais ou metáforas de tal modo que fortalecem certas ideias e passam a pensar de um modo específico. Essas reiterações também podem ocorrer por meio de afirmações ou de formulações negativas, tais como "não pense, "não é", pois, tanto em um caso quanto no outro, os mesmos quadros ou metáforas podem ser ativados e fortalecidos.

Podemos relacionar esse posicionamento de Lakoff (2009) acerca do efeito da repetição nas mentes humanas ao postulado de Perelman e Olbrechts-Tyteca (2002 [1958] a respeito de a presença ser favorável à argumentação, uma vez que o dito consiste em um recorte privilegiado, e o não dito, em um apagamento. Dessa maneira, tem-se que o dito e o silenciado intercalam-se na tessitura dos sentidos, ordenando-se em meio a processamentos cognitivos e pragmáticos, agindo a favor de quem o faz, uma vez que são as informações postas em evidência que darão o encaminhamento de associações cognitivas específicas e atingirão as mentes de quem as recebem, influenciando-as, convencendo-as.

Para Turner (2014), certas ideias, quando postas em discurso, podem influenciar outras mentes e, de modo consequente, mudar o mundo. Assim, entendemos um ponto central do papel da cognição na argumentação: por um lado, é via discurso que reconhecemos novas possibilidades de se pensar sobre algo e agir sobre mundo; por outro, é na mente que a realidade do ser se constrói para que ele mude o mundo.

Nesse viés, a compreensão da situação em que se está orienta os mecanismos selecionados para argumentação, quer ela seja pública ou privada. Em específico, os políticos agem linguístico-discursivamente, tendo em vista o modo como aprenderam a ver o campo da ação política no decorrer de suas experiências individuais e coletivas. É desse modo que

\footnotetext{
2 De modo geral, Lakoff (1987), em sua Teoria dos Protótipos, postula que os processos de categorização, identificáveis na linguagem, relacionam-se a modelos cognitivos. Nesse viés, o estudioso elabora um estudo acerca dos Modelos Cognitivos Idealizados (MCl)- estruturados via crenças, valores, objetivos etc. que servem como estímulos -, entre os quais está a metáfora.

3 Embora este trabalho dê atenção para a metáfora conceptual, o conceito de frame é, recorrentemente, apresentado por Lakoff (2009). Para ele, frame consiste de estruturas mentais que moldam a maneira como vemos o mundo e agimos nele e sobre ele.
} 
entendemos que os processos sociocognitivos e os discursivos entrelaçam-se e constroem as situações típicas do jogo da política. De acordo com Marcuschi (2008, p. 228): “[...] nossa compreensão está ligada a esquemas cognitivos internalizados, mas não individuais e únicos. Assim, a percepção é, em boa medida, guiada e ativada pelo nosso sistema sociocultural internalizado ao longo da vida".

A partir dos pressupostos de Lakoff (2009), o sentido dos símbolos não está em sua relação direta com as coisas do mundo, mas sim nas conexões neurais, que criam relações entre linguagem e estruturas cerebrais (frames, metáforas etc.). Nesse viés, para o autor, todo sentido é corporificado, isto é, passa pela condições cognitivas, próprias dos seres humanos, os quais as ativam para apreender e compreender dadas circunstâncias:

Toda percepção significativa e toda ação são mediadas por nossos cérebros, quer sejam físicas, sociais, emocionais ou interpessoais; entretanto, os cérebros sozinhos, sem os corpos e as interações físicas e sociais, nada fazem. É o cérebro unido ao funcionamento do corpo, no mundo físico e social, que dá sentido e motivos reais (LAKOFF, 2009, p. 232)

Nesses processos sociocognitivos, é pelo discurso que ativamos, comunicamos, regulamos e alteramos nossa compreensão a respeito daquilo que nos cerca e de nós mesmos. Essa função social e cognitiva dos discursos fá-los poderosos, já que as práticas discursivas permitem que ideias sejam relacionadas de tal modo que não se pode apartá-las de nossas atuais condições de acesso ao conhecimento social e de nossa maneira de nos relacionar com ele.

Conforme os estudos de van Dijk (2016), que partem de uma relação entre discurso, cognição e sociedade, existem dois tipos de estruturas cognitivas subjacentes aos discursos. A primeira refere-se à cognição pessoal e diz respeito aos modos como falantes de dadas comunidades linguísticas, epistêmicas e sociais desenvolvem seus discursos e compreendem os demais.

Ao mesmo tempo em que os falantes utilizam-se da linguagem individualmente, eles o fazem no interior de situações interacionais específicas, as quais são adquiridas, mudadas e reproduzidas em dada sociedade, de modo a construir a cognição social, baseada em crenças,

\footnotetext{
${ }^{4}$ No original: All meaningful perception and action is mediated by our brains, whether physical, social, emotional, or interpersonal. But brains alone without bodies and physical and social interactions do nothing. It is the brain connected to the entire body functioning in the physical and social world that gives meaning and grounds real reason.
} 
atitudes e ideologias compartilhadas. Sendo assim, o pessoal e o social interligam-se no processamento discursivo e, tal como defendemos, no argumentativo.

Essa interligação entre a cognição pessoal e a social pode explicar muitos procedimentos linguístico-discursivos, relativamente estabilizados, em dada sociedade e em cada época, assim como é o caso dos gêneros discursivos políticos e da argumentação, neles, selecionada. Dessa maneira, debates, entrevistas, discursos institucionais proferidos, entre outros, podem ser compreendidos em termos de uma cognição política, por conta de os políticos não apenas usarem a linguagem, mas também pensarem sobre ela e a respeito de seu uso. Esse posicionamento leva em consideração que existe uma base cognitiva atrelada à noção de ação, distanciando-se, portanto, de um conceito behaviorista, no interior do qual se entende a existência de comportamentos conduzidos apenas pela observação. Desse modo, defendemos o postulado de que, na cognição política, existem frames molduras de encontros políticos, gêneros discursivos específicos - a partir dos quais a argumentação é regulada.

Nesse direção, os políticos, como participantes de uma comunidade linguística, epistêmica e social, agem, no e pelo discurso, a partir de suas experiências individuais e coletivas, selecionando mecanismos linguísticodiscursivos de acordo como compreendem as situações de comunicação nas quais estão inseridos - ativando uma memória episódica. No caso da política externa, existe a necessidade de se conhecer as regras do jogo, os jogadores, os papéis de cada um e os caminhos, para que o discurso esteja engajado, e a argumentação, adequada. Por essa razão, entendemos que esses discursos não são ingênuos, ao contrário disso, são elaborados por meio de uma motivação de caráter sociocognitivo, na qual a ideia de persuadir e de convencer é, também, subjacente.

Para van Dijk (2016, p. 16), os membros de um grupo são capazes de inferir os objetivos e as opiniões de outros integrantes, em razão de partilharem atitudes sociais específicas. Nessa acepção, os políticos e outros profissionais envolvidos constroem noções e armazenam, em suas memórias, experiências sobre encontros específicos, que são ativadas localmente. Para o autor (2016, p. 8):

A teoria cognitiva consiste, por um lado, de uma dimensão pessoal de modelos mentais pessoais (i) dos eventos sobre os quais se fala ou se escreve, e (ii) da própria situação comunicativa (modelos contextuais), e por outro de uma 
dimensão social que consiste de crenças, conhecimento, atitudes e ideologias socialmente compartilhadas - que controlam os modelos mentais pessoais, e indiretamente todo discurso.

Partindo dessa perspectiva, pode-se afirmar que, no interior da política externa, existem ocorrências particulares a depender dos participantes e dos objetivos em curso. O tratamento discursivo e argumentativo dado a políticos da CPLP, provavelmente, difere daquele apresentado a um Estado em especial, ou mesmo, proferido em um encontro bilateral entre Brasil e China, embora haja pontos em comum, próprios da política global.

Mesmo que as estratégias argumentativas se repitam, tal como é o caso da busca por comunhão (por fazer parte de um modelo mental mais geral), os caminhos podem variar, pois ativam-se especificidades do modelo de contexto: quadro de referências, construção de identidades, apelo às paixões, alusões típicas, metáforas etc. Assim é que se pode dizer que o comportamento linguístico-discursivo é sempre atualizado à situação comunicativa da mesma medida que os modelos de contexto estão em contínua construção (VAN DIJK, 2016, p. 10).

O estudo de Charteris-Black (2011, 2014) sobre as circunstâncias cognitivas da argumentação política também apontam para o estatuto cognitivo do uso da linguagem em decorrência dos conhecimentos que os políticos possuem acerca de seus interlocutores e do ambiente comunicativo no qual estão inseridos ou em que vão interagir.

Nessa acepção, o autor estende os fatores relacionados à dinâmica da argumentação, apresentada por Aristóteles - logos, pathos e ethos -, de modo a incluir os processos cognitivos e os pragmáticos. Para Charteris-Black, a argumentação política tem por função convencer o interlocutor que o locutor está certo em suas posições e que tanto um quanto outro partilham dos mesmos interesses. Dessa forma, para que haja confiança acerca dos propósitos do orador e do grupo que ele representa, o ethos de integridade corresponde a um pré-requisito de qualquer prática argumentativa da política. Caso contrário, a imagem de si comprometerá o desempenho da argumentação.

À medida que o orador constrói acerca de si uma imagem de confiança, a argumentação política também deve demonstrar racionalidade (logos) em suas propostas, a fim de surtir o efeito de pensar corretamente. Além da demonstração da razão, o orador e seu grupo necessitam atingir um impacto emocional (pathos), pois, para Charteris-Black (2014), é desse modo que se 
criam empatia, humor ou outros sentimentos, por meio dos quais os interlocutores ficam engajados com a tese defendida, surtindo o efeito de esta parecer certa.

Charteris-Black (2014) também inclui as representações mentais - via metáforas conceptuais, entre outras maneiras - como parte da argumentação política, tendo em vista que tais processos cognitivos estabelecem o efeito de contar a história certa. A ativação de um conjunto de frames e suas associações possibilitam que sejam criadas ou fortalecidas certas representações mentais que influenciam os interlocutores a verem dadas situações de modo específico e, por consequência, a se tornarem suscetíveis à aderência das propostas. Por último, o autor assinala a importância de apresentar uma aparência adequada do locutor, viabilizada no modo como ele se veste, gesticula etc.

Por tudo o que se expôs, podemos dizer que, instanciada no uso da argumentação política, a cognição cumpre papel significativo, por conta dos processos que ela envolve na orientação de perspectivas, a partir das quais os participantes de dada interação tomam decisões, quer sejam relacionadas ao desenvolvimento dos discursos, quer sejam correspondentes ao convencimento e à persuasão desses discursos.

Desse modo, é via esses processos de compreensão e de conceptualização do mundo que a cognição está atrelada às negociações entre as partes envolvidas e ao planejamento das práticas do campo político, nas quais os discursos ancoram as construções conceptuais e as situações comunicativas. Em específico, no caso da política global, acreditamos na existência de uma cognição política a partir da qual os participantes tomam decisões, comportam-se de certa maneira e desenvolvem seus discursos e argumentação.

2. Um caminho da argumentação política global: a construção da Língua Portuguesa como agente

Os processos cognitivos da política global relacionam-se a circunstâncias complexas em termos da variedade de especialistas e de campos de atuação que estão envolvidos no momento em que os discursos públicos são elaborados e proferidos. Legisladores, líderes de negócios, jornalistas, entre outros, comunicam-se com os políticos, em situações públicas ou privadas/secretas. Dessa maneira, Chilton e Lakoff (2005) propõem um 
contínuo entre o discurso especializado/secreto e o do cotidiano da política em seu viés internacional, dando ênfase às conceptualizações metafóricas, implicadas nessas práticas linguageiras, realizadas pelos atores políticos.

Ressaltamos que, para Chilton e Lakoff (2005), assim como para Lakoff e Johnson (1980), as metáforas conceptuais não consistem de simples palavras ou expressões, ou mesmo, de noções imaginosas, mas sim de modos de corporificação do pensamento e de estruturação dos discursos da política, indicando o modo de pensar sobre esse tipo de situação. Elas correspondem a um dos sentidos primários por meio dos quais conceptualizamos o mundo. Nesse viés, esses estudiosos (2005, p. 38) afirmam que: "Pensamos, automaticamente, sem esforço e sem estarmos cientes do fato de estarmos usando as metáforas com que crescemos e as quais aceitamos inquestionavelmente" ${ }^{5}$.

Entre as metáforas conceptuais examinadas por Chilton e Lakoff (2005) nos discursos da política global, a personificação do Estado (ESTADO É PESSOA) consiste da principal. A esse respeito, os autores assinalam que, frequentemente, organizações são personificadas e o mesmo ocorre com os Estados, pois estes “tornaram-se a mais poderosa forma de organização política nos últimos quatrocentos anos, e tiveram origem no poder individual dos príncipes" (p.39).

Por meio da personificação, os Estados passam a se relacionar uns com os outros como pessoas as quais podem ser amigas, inimigas, vizinhas, clientes, entre outras relações no interior das quais se torna possível criar confiança ou desconfiança, agressividade ou paz, força de vontade, estabilidade ou instabilidade, cooperação, intransigência, empreendimento etc. (CHILTON, LAKOFF, 2005). Nessa mesma direção, quando se procede a construir metaforicamente a personificação de nações, as entidades ativadas, tais como os povos e seus países, passam a ser caracterizadas como agressivas ou pacíficas, cooperativas ou não, empreendedoras ou não etc.

No caso dos discursos da CPLP, temos visto (PALUMBO, 2014) que a construção dos Estados-membros como pessoas é procedimento recorrente e pista indicativa de uma tentativa de manter vínculos emocionais e políticos entre os países, favorecendo a ideia de que falantes de uma mesma língua

\footnotetext{
${ }^{5}$ No original: We think automatically, effortlessly, and without being aware of the fact that we are using metaphors with which we have grown up, metaphors we have accepted unquestioningly.

${ }^{6}$ No original: [...] have become the most powerful form of political organization over the last four hundred years, and have their origins in the power of individual princes.
} 


\section{$\mathrm{El} \square \mathrm{dA}$}

Revista Eletrônica de Estudos Integrados em Discurso e Argumentação, Ilhéus, n. 18, abr.2019.

trazem um traço comum, relacionado à noção de família ou a de amigos.

Do ponto de vista argumentativo, Perelman e Olbrechts-Tyteca (2002 [1958]) discutem a respeito da relação entre membros e seu grupo. Nesse processo análogo, não só a (re)construção da imagem de um grupo depende das ações de seus membros, mas também o mesmo tanto, e às vezes mais, do comportamento de quem não é membro, uma vez que é na diferença que também se constitui a identidade.

No discurso do Presidente Taur Matan Ruak sobre o décimo terceiro aniversário da Restauração da Independência de Timor-Leste, examinamos a seleção "estes países irmãos" como referência aos Países Africanos de Língua Oficial Portuguesa. No que diz respeito ao uso da metáfora aliado à argumentação política global, identifica-se a personificação de países como meio de encaminhar a ideia de haver, entre eles, uma relação familiar, de cooperação e de confiança, caso o conceito de família dos participantes esteja vinculado a essas relações.

Chilton e Lakoff (2005) afirmam que a personificação de Estados está subjacente à política internacional. A relação estabelecida entre pessoa, sociedade e Estado, por consequência da ativação de certos domínios conceptuais, dependerá de outros conceitos pré-existentes nas mentes dos envolvidos.

Nesse processo sociocognitivo complexo de dar sentidos aos referentes ativados nos discursos da política, os conceitos sobre os políticos merecem especial atenção, por conta de suas imagens estarem diretamente ligadas às possíveis associações motivadas no momento da enunciação. Assim como Estados podem ser vistos a partir da imagem que se cria de seu povo, a depender das condições específicas de um encontro, também podem ser atrelados às de seus políticos e de suas posições políticas nos cenários interno e externo.

Além do mais, em consonância com Chilton e Lakoff (2005), quando Estados são construídos como pessoas na política internacional, deve-se considerar que toda pessoa tem um corpo que cresce, fica maduro e declina, bem como pode ser forte, fraco, bem desenvolvido ou não, saudável ou doente. Essas características atreladas a um Estado ou a uma comunidade política darão o entorno necessário para conduzir o efeito argumentativo almejado, quer seja para atrair os interlocutores com a ideia de força e de 
capacidade de realizar bons negócios e parcerias, quer seja para desqualificar um poder em curso em favor das teses defendidas.

Os autores, ainda, assinalam que a maturidade de um Estado pode ser vista pela sua industrialização, de modo a também explicar a noção de desenvolvimento e subdesenvolvimento. De fato, devemos salientar que a imagem de cada um sempre estará atrelado aos outros via um processo análogo tanto com aqueles que são seus aliados quanto com os que não são, assim como já discutimos anteriormente. Assim acreditamos ser o caso da construção da Língua Portuguesa nos discursos dos países-membros da CPLP.

No discurso proferido por José Sarney, na Casa do Senado Federal, em 2006, o político procede à narração dos feitos da Língua Portuguesa a partir de elementos linguísticos que conduzem a um processo de significação via verbos agentivos: "ela saiu de uma pequena faixa de terra", "a língua que atravessava os mares", "Ela atravessou o Estreito de Málaga, foi pela costa da China e chegou a Nagasaki, onde deixou e levou palavras", "Até onde chegou a Língua Portuguesa". Esse modo de apresentar o idioma pode ser examinado nos próximos segmentos:

(1)

A Língua Portuguesa é um milagre, porque, como nós sabemos, ela saiu de uma pequena faixa de terra. Ela era quase um dialeto do espanhol, como era o galego. E ela, não tendo terras para ser falada, foi a primeira língua universal, porque foi a língua dos navegantes, a dos conquistadores, a língua que atravessava os mares; ela foi a língua do comércio daquele tempo, em fins do século XV e no século XVI.

Para essa aventura da Língua Portuguesa, certamente, tivemos a contribuição do grande poeta que participou dessa aventura dos mares, o poeta Camões, que estabeleceu, quando escreveu Os Lusíadas, as regras que fixaram definitivamente a sintaxe e as regras fundamentais da Língua Portuguesa.

Foi tão importante essa Língua que não foi só falada, mas também transformouse numa língua que gerou outras línguas como, por exemplo, o creoulo de Cabo Verde, em que $90 \%$ das palavras são portuguesas, ou o papiamento de GuinéBissau, e outras línguas que geraram línguas locais, faladas popularmente.

Ela atravessou o Estreito de Málaga, foi pela costa da China e chegou a Nagasaki, onde deixou e levou palavras. Basta dizer que cinqüenta e quatro palavras ainda hoje dicionarizadas têm origem de palavras japonesas. Até onde chegou a Língua Portuguesa!

Em razão de o objeto de discurso ser integrado a outras formulações linguísticas e às metáforas em curso, entendemos a importância de considerar 
os momentos de sua ativação. Em (1), o sentido metafórico de Língua Portuguesa tece-se durante a narração de uma história sobre sua expansão, na qual o idioma é tratado como protagonista. No esquema ORIGEMPERCURSO-META, a superioridade dada às ações do passado permite a construção de uma língua conquistadora e aventureira. A seleção "essa aventura da língua portuguesa" reforça essa concepção.

Além disso, o idioma é construído com características que são esperadas por parte dos políticos do campo internacional, principalmente no que diz respeito à força, à competitividade, à competência de conquistar outros territórios. Podemos, ainda, dizer que a atitude de Sarney orienta para mais uma direção argumentativa: a de prestigiar, em especial, a imagem de Portugal. Há pistas desse procedimento tanto na construção LíNGUA PORTUGUESA É AGENTE quanto na ativação do objeto de discurso "o grande poeta que participou dessa aventura", "o poeta Camões, que estabeleceu, quando escreveu Os Lusíadas, as regras que fixaram definitivamente a sintaxe e as regras fundamentais da Língua Portuguesa". Assim é que a argumentação recai, novamente, para a relação membros e grupo, na qual os valores atribuídos a um se estendem a todos.

Na sequência do pronunciamento de José Sarney, a Língua Portuguesa vai ganhando outros atributos. Nessa ocasião, os verbos "matar e dominar" conduzem a ideia de um agente que possui força de batalha. Posteriormente, apresentam-se ações-processo por meio das quais se cria o efeito de estar diante de cenas de desbravamento feito pela Língua Portuguesa - "Ela foi levando, foi andando, foi abrindo caminhos, foi abrindo o território onde não tinha mares".

(2)

Portanto, essa idéia de se reunir povos de Língua Portuguesa também tem um efeito grandemente político. Recordo-me de que estava com o Presidente José Eduardo dos Santos, Presidente de Angola, há alguns anos, e ele me dizia, logo depois da Guerra da Independência, que ele estava fazendo um esforço muito grande para ver se renascia e fortificava os dialetos locais. Eu tive a oportunidade de dizer-lhe que não perdesse de vista a importância que tinha a língua para a unidade nacional, porque hoje se sabe que língua tem uma grande força política e essa Língua havia determinado a unidade nacional, como no Brasil, onde é quase um dogma que se repete sempre. Essa unidade seria impossível, com essa extensão territorial que tem o Brasil, se não tivéssemos a Língua Portuguesa. Ela aqui chegou, matou os dialetos que aqui existiam e se tornou uma língua geral que dominou todo o nosso País. Por uma ironia da História, ela parou justamente no contraforte dos Andes, onde encontrou uma outra língua, o castelhano, de onde ela tinha saído, na Península Ibérica, depois 
de ter tido essa grande aventura dos mares. Aqui, no Brasil, ela teve a mesma destinação que teve nos mares. Foi uma língua também de andarilhos, de bandeirantes, de desbravadores. Ela foi levando, foi andando, foi abrindo caminhos, foi abrindo o território onde não tinha mares. Então, de uma língua falada nos mares, transformou-se também numa língua continental. Hoje, 230 milhões de pessoas no mundo inteiro falam o português, uma pequena língua, de um pequeno espaço de território onde era Portugal, que se transformou numa língua universal.

Existem pistas indicativas do papel retórico da metáfora LíNGUA PORTUGUESA É AGENTE, que corresponde ao favorecimento dado por um mapeamento cognitivo complexo de levar a ideia do poder da língua portuguesa, no sentido de indicar que ela pôde, no passado, agir a favor da conquista, de crescimento e, assim, no presente, seguir na mesma direção.

De modo geral, o exame do corpus leva-nos a retomar os pressupostos de Lakoff (2009) acerca da força da linguagem de evocar memórias, ou mesmo, de mudá-las, moldá-las, a fazer que a história de uma passado possa ser reconstruída. De fato, é o que ocorre nos discursos políticos da CPLP, em que a Língua Portuguesa assume papel central na argumentação, via a ativação de objetos de discurso vinculados em meio a momentos de seleção de memórias da história, reconduzidas e ajustadas ao novos valores da política global, que já não são os mesmos daqueles da época das navegações. Assim é que se apagam marcas de um processo histórico de colonização e se orientam maneiras específicas de narrar a história dos países-membros, especialmente, com a atenção voltada para a cumplicidade, a cooperação e a partilha de interesses.

\section{A participação do esquema LIGAÇÃO nas práticas de argumentação política global}

Os estudos de Perelman e Olbrechts-Tyteca (2002 [1958]) revelam que a argumentação também atua via o estabelecimento de uma comunhão entre as partes envolvidas. Um discurso que evidencia o que é comum em um passado, ou mesmo, em uma tradição, pode orientar um olhar avaliativo por meio do qual traços de culturas diversas interligam-se, de maneira a criar uma série de associações que fortalecem a acepção de unidade e de pertencimento. Trata-se de um procedimento argumentativo, por meio qual se apresenta um conjunto de características relativas a um objeto de discurso, para se atingir um valor de verdade, alinhado à proposta do dizer. 
Tal procedimento argumentativo de se voltar para o efeito de pertencimento, geralmente, vem acompanhado de seleções linguísticodiscursivas que podem ativar afetividades particulares, enternecimento diante certas memórias e do orgulho de uma comunidade, pois se trata de empenhos em fazer os interlocutores participarem, de modo ativo, daquilo sobre o que se fala e se defende. Os efeitos dependerão do encaminhamento dado ao discurso, da inter-relação dos argumentos selecionados e do momento sóciohistórico da enunciação.

Entendemos que, nos efeitos de pertencimento, existe uma base cognitiva socialmente compartilhada, que pode ser acionada em ocorrências de metáforas em determinados discursos. Acreditamos ser o caso dos esquemas conceituais básicos indicados por Lakoff e Johnson (1980) e Lakoff (1987): CONTÊINER, PARTE-TODO, LIGAÇÃO, CENTRO-PERIFERIA, ORIGEMPERCURSO-META, PARA CIMA-PARA BAIXO. Para os autores, esses esquemas são oriundos da experiência corpórea e podem ser acionados por metáforas. Para nós, eles também podem participar como base tanto de construções de noções de objetos de discurso quanto dos processos de significação e de seus efeitos de caráter argumentativo.

Observamos, em nossas análises, que esse efeito de pertencimento está atrelado à ativação do esquema LIGAÇÃO, recorrentemente localizado nos discursos examinados, tal como é o caso do discurso de Dilma Rousseff, pronunciado durante a cerimônia de entrega da Ordem do Mérito Cultural 2012, ocorrida em Brasília, em 2012. Observamos que a seleção "impulsionados pela língua comum que nós compartilhamos" encaminha a ideia de haver um elemento de ligação entre pessoas que possuem traços culturais distintos. Esse procedimento é alicerçado pela metáfora do conduto (LíNGUA É CONDUTO) via o verbo "impulsionar" e é indicativo de uma ação argumentativa que tem por base o esquema LIGAÇÃO. Examinemos os segmentos subsequentes:

\section{(3)}

É interessante que nós não temos um traço hegemônico, e é muito bom que seja assim: impulsionados pela língua comum que nós compartilhamos. E pela origem desta Língua Portuguesa, nós fizemos dela uma nova língua, recebendo influências riquíssimas dos indígenas, dos africanos, dos nossos vizinhos de origem espanhola, dos europeus, dos italianos, alemães, franceses, búlgaros, dos árabes, dos judeus, dos palestinos e de vários povos asiáticos - japoneses, chineses, enfim, de uma parte expressiva da humanidade. Por isso, só podia dar certo. 


\section{(4)}

Poucos países do mundo tiveram tanta sorte e poucos povos do mundo receberam de maneira tão entranhada e definitiva, e ao mesmo tempo, generosa, o processo de miscigenação. Sobre o guarda-chuva unificador de uma língua comum e de uma história de convivência, nem sempre pacífica, vamos nos lembrar, entre os habitantes de diferentes regiões. Mas necessariamente, unificadora. A pluralidade e a diversidade são grandes trunfos de nossa formação como povo e como nação.

Não ocorre negação das diferenças existentes entre os povos. Ao contrário disso, a tese defendida corresponde ao poder de uma língua de diminuir distâncias. É no processo referencial que se tecem, nesse viés, as propriedades desse objeto de discurso: "língua comum que nós compartilhamos", "esta Língua Portuguesa”, "o guarda-chuva unificador de uma língua comum e de uma história de convivência, nem sempre pacífica”.

A seleção "o guarda-chuva unificador" pode favorecer a associação entre a imagem evocada desse objeto e a da CPLP. Os países-membros podem ser compreendidos em termos de hastes, ligadas pela estrutura da língua e da história comuns e cobertas por uma armação a qual leva a ideia de proteção. Esta alinha-se à noção do poder das parcerias e ao de Lusofonia. Nessa direção, ocorre alusão ao passado para justificar o presente, de maneira a orientar efeitos de pertencimento.

No discurso de José Luís Guterres, pronunciado em Dili, em 2011, a seleção "o capital precioso que temos em comum" traz outras características à Língua Portuguesa via o esquema LIGAÇÃO:

\section{(5)}

[...] Acredito que este Fórum de discussão possa também trazer vantagens a toda a Comunidade de Países de Língua Portuguesa, pois quando nos fazemos representar em qualquer parte do mundo, estamos a materializar e a projectar 0 capital precioso que temos em comum.

Do ponto de vista argumentativo, temos que, estruturada pelo esquema LIGAÇÃO, na formulação "o capital precioso que temos em comum”, os termos "capital" e "precioso" ancoram-se, dando o valor de raridade, de prestigio à Língua Portuguesa. Nessa acepção, podemos afirmar que, em nossa sociedade, quanto mais raro for um objeto, tanto mais prestígio terá. Não é possível contestar a hierarquia do valor do raro, no entanto, a contestação pode voltar-se para a raridade do objeto, a qual deve ser provada ou justificada. 
No procedimento em exame, a força argumentativa da formulação referencial ocorre por meio do epíteto, a partir do qual se apresenta qualificação. Em razão do efeito de fato que suscita, assim como Perelman e Olbrechts-Tyteca (2002 [1958]) assinalam, não há necessidade de justificativas. O objeto Língua Portuguesa e seu valor de preciosidade são apresentados como um fato partilhado pelos participantes e revelam-se como legitimadores da CPLP, uma vez que se orienta a ideia de que todos possuem o que é raro ("o capital precioso que temos em comum"). Trata-se da construção da língua como objeto de poder simbólico. É ela que une, é por ela que se unem, é por meio dela que se fortalecem. Nesse caminho, os políticos da CPLP disseminam a ideia de uma língua de prestígio e de força, associando-a ao grupo, o qual busca pelo prestígio e pelo poder no campo internacional.

Trata-se, também, de uma estratégia de caráter sociocognitivo. Ao tomarem o objeto Língua Portuguesa, os políticos vão delineando noções de modo não ingênuo, mas sim alinhadas com as propostas de suas políticas globais. Nessas ocasiões, procedem ao afastamento da Língua, concebendo-a, por vezes, com as características de objetos empíricos (um laço, a base), das quais partem para criar uma imagem específica de uma aliança firme, reiterando-a, fortalecendo-a a cada discurso. Dessa forma é que entendemos a participação do esquema LIGAÇÃO, por meio do qual noções de comunidade e aliança são construídas.

\section{Conclusão}

O exame dos discursos da CPLP leva-nos a afirmar que a seleção das metáforas possui caráter argumentativo, uma vez que identificamos a ocorrência de orientações argumentativas por ocasião das associações, possivelmente, promovidas entre o objeto de discurso Língua Portuguesa e outros que as metáforas suscitam concomitantemente. Ao tratar o idioma como agente, é possível que valores sejam ativados e sirvam como objetos de acordo, de consenso. A relação entre membros e grupo, proposta na nova retórica, ganha dimensão nessa construção, haja vista que a imagem de uma pessoa destemida, desbravadora de territórios e vencedora por suas conquistas dá sentido específico à CPLP e indica as ações que os países devem tomar, que consistem das mesmas da Língua Portuguesa como agente.

Desse modo, o procedimento recai sobre as ações que os políticos devem executar, correspondentes à propagação da CPLP por meio do idioma. 


\section{$\mathrm{EI} \square \mathrm{dA}$}

Indica-se a direção do jogo, bem como procede-se a uma linha de raciocínio a qual valida a proposta e caminha para a ideia de que todos os membros possuem os mesmos interesses. Ocorre, pois, a articulação do logos e das representações mentais, podendo promover os efeitos de pensar certo e de contar a história certa, indicados por Charteris-Black (2011, 2014) como estratégias da argumentação política.

O procedimento de trazer para uma língua a noção de elemento que une os países-membros permite uma organização do mundo político, no qual a CPLP se fortalece como comunidade que se propõe a reunir Estados, com a justificativa de terem uma língua comum. Trata-se do apelo ao efeito de comunhão, por meio do qual as partes tenderão a construir/reforçar uma identidade política, a ativar sentimentos de pertencimento e a estabelecer raciocínio a partir desse viés. A ação argumentativa recaiu sobre o "contar a história certa" (CHARTERIS-BLACK, 2011, 2014).

\section{Referências}

CHARTERIS-BLACK, Jonathan. Politicians and rhetoric: the persuasive power of metaphor. Basingstoke: Palgrave Macmillan, 2011.

. Analysing Political Speeches: rhetoric, discourse and metaphor. Basingstoke: Palgrave Macmillan, 2014.

CHILTON, Paul; LAKOFF, George. Foreign policy by metaphor. In: SCHAFFNER, Christina; WENDEN, Anita L. (Eds.). Language and Peace. Amsterdan: Taylor e Francis e-Library: 2005. p.37-60.

LAKOFF, George. Women fire and dangerous things: what categories reveal about the mind. Chicago: University of Chicago Press, 1987.

. The political mind. A cognitive scientist' guide to your brain and its politics. New York: Penguin Books, 2009.

LAKOFF, George; JOHNSON, Mark. Metaphors We Live By. Chicago: Chicago University Press, 1980.

MARCUSCHI, Luiz Antônio. Produção textual, análise de gêneros e compreensão. São Paulo: Parábola, 2008.

PALUMBO, Renata. Referenciação, metáfora e argumentação no discurso presidencial. Série Produção Acadêmica Premiada. São Paulo: Faculdade de Filosofia, Letras e Ciências Humanas, FFLCH-USP, 2014. Disponível em: http://www.spap.fflch.usp.br/sites/spap.fflch.usp.br/files/Renata_Palumbo.pdf 
PERELMAN, Chaim; OLBRECHTS-TYTECA, Lucie. Tratado da argumentação: a Nova Retórica. Tradução: Maria Ermantina Galvão. São Paulo: Martins Fontes, 2002 [1958].

TURNER, Mark. The origin of ideas: Blending, Creativity and the Human Spark. New York: Oxford, 2014.

VAN DIJK, Teun Adrianus. Discurso-cognição-sociedade: estado atual e perspectivas da abordagem sociocognitiva do discurso. Letrônica, Porto Alegre, v. 9, n.esp., p. 829, 2016.

\section{Forma de citação sugerida}

PALUMBO, Renata. Argumentação e sociocognição nos discursos da Comunidade de Países de Língua Portuguesa. EID\&A - Revista Eletrônica de Estudos Integrados em Discurso e Argumentação, llhéus, n. 18, p. 104-121, abr.2019. DOI dx.doi.org/10.17648/eidea-18-2304. 